\title{
Changes in c-fos mRNA Expression in Rat Brain during Odor Discrimination Learning: Differential Involvement of Hippocampal Subfields CA1 and CA3
}

\author{
Ursula S. Hess, ${ }^{1}$ Gary Lynch, ${ }^{1,2}$ and Christine M. Gall ${ }^{1,3}$ \\ ${ }^{1}$ Department of Psychobiology, ${ }^{2}$ Center for the Neurobiology of Learning and Memory, and ${ }^{3}$ Department of Anatomy \\ and Neurobiology, University of California at Irvine, Irvine, California 92717
}

Levels of c-fos mRNA were measured with in situ hybridization to test for behaviorally dependent changes in neuronal activity in three subdivisions of hippocampus and in components of the olfactory and visual systems. In rats that performed a well-learned nose-poke response for water reward, c-fos mRNA levels were broadly increased, relative to values in home cage-control rats, in visual cortex, superior colliculus, olfactory bulb, and, to comparable levels, regions CA3 and CA1 of hippocampus; hybridization was not increased in the dentate gyrus. In rats first trained on the nose-poke behavior and then required to discriminate between two odors for water reward, the increase in c-fos mRNA was generally not as great and was more regionally differentiated. Thus, in olfactory bulb, hybridization was more greatly elevated in lateral than medial fields, thereby exhibiting regional activation corresponding to the topographic representation of the predominant odor sampled in the discrimination task. In hippocampus of odordiscrimination rats, c-fos mRNA levels were far greater in the region $\mathrm{CA} 3$ than region $\mathrm{CA} 1$, but remained at cage control values in stratum granulosum. Interestingly, c-fos mRNA levels in each hippocampal subdivision were highly correlated with levels in other regions (e.g., visual cortex) for home cage controls but not for rats in the two behavioral groups. Thus, c-fos mRNA levels in cage-control rats appeared to be regulated by some generalized factor acting throughout much of the brain (e.g., arousal), while odordiscrimination performance changed the pattern of expression within hippocampus, and allowed for a differentiated response by olfactory regions to emerge. These findings suggest that hippocampus possesses multiple modes of functioning and makes contributions to behavior that vary according to task demands.

[Key words: gene expression, in situ hybridization, odor discrimination, olfactory bulb, piriform cortex, visual system, hippocampus]

\footnotetext{
Received Aug. 17, 1994; revised Feb. 10, 1995; accepted Feb. 14, 1995.

We thank Thomas Nguyen for help in training animals and Dr. Julie Lauterborn for assistance in preparing the manuscript. In addition, we are grateful for valuable discussions with Drs. Richard Granger and Ben Bahr. This work was supported by HD24236 and Research Scientist Development Award MH00974 to C.M.G., ONR NO0014-89-J-1255, and Research Scientist Award 5 K05MH00358 to G.L., and NIMH Predoctoral Fellowship MH10510 to U.S.H.

Correspondence should be addressed to Dr. Christine M. Gall at the above address.

Copyright $(\mathcal{C} 1995$ Society for Neuroscience $0270-6474 / 95 / 154786-10 \$ 05.00 / 0$
}

Identifying brain systems that exhibit relatively higher or lower levels of neuronal activity in association with the encoding and use of memory is an important goal of behavioral neuroscience. Induction of the proto-oncogene c-fos has considerable potential with regard to this problem. Depolarization rapidly stimulates c-fos transcription in a $\mathrm{Ca}^{2+}$-dependent manner (Greenberg et al., 1986; Morgan and Curran, 1986), with the resultant increase in mRNA and protein providing a marker for active neurons (Hunt et al., 1987; Morgan et al., 1987; Sagar et al., 1988); in accord with this, in situ hybridization and immunocytochemical studies have established a correspondence between c-fos mRNA expression, Fos staining, and the uptake of 2-deoxyglucose, a marker for metabolic activity (Sharp et al., 1989; Ehret and Fischer, 1991; Guthrie et al., 1993). These studies on well-defined sensory/motor systems confirm that areas containing neurons with high levels of fos induction are targets of the stimuli used as test probes. Induction of c-fos has also been obtained in certain learning paradigms. Increased levels of mRNA were reported in hippocampus and visual cortex of rats following training on a two-way active avoidance task (Nikolaev et al., 1992), as were differential concentrations in the brainstem of rabbits after pseudoconditioning versus conditioning of the nictitating membrane reflex (Irwin et al., 1992). Enhanced c-fos expression also occurred in the accessory olfactory bulb of female mice in correlation with the encoding of memory for male pheromones (Brennan et al., 1992).

The present studies used c-fos mRNA expression to investigate the involvement of visual, olfactory, and hippocampal regions in the acquisition of a two-odor discrimination. Importantly, they tested the possibility that the subfields of hippocampus are differentially active during initial learning of an olfactory discrimination. A number of hypotheses have been advanced regarding the role of hippocampus in memory such as, for example, that it promotes consolidation in other brain regions (Squire et al., 1984; Squire, 1986), or encodes long-term information about spatial relationships (O'Keefe and Nadel, 1978) or the configuration of spatial and other types of cues (Wicklegren, 1979; Halgren, 1984; Squire et al., 1984; Lynch, 1986; Eichenbaum et al., 1992), or it provides for a kind of "working memory" of behaviors executed in the recent past (Olton et al., 1979; Olton et al., 1980). Less attention has been given to the possibility that the subdivisions of the hippocampus might be differentially active, depending upon task demands, allowing for the composite structure to play multiple roles in learning and other behaviors. However, Winson (1984) demonstrated that at each juncture of the trisynaptic chain there is either a selective re- 
striction or a lack of restriction of neuronal transmission, the effect depending on the behavioral state of the experimental animal. Along the same lines, Buzsaki (1989) proposed that the two principal cell types of the hippocampus, the pyramidal neurons and granule cells, are maximally active during different behaviors. Recently, Sybirska et al. (1994) found limitcd subfields of region CA1, but not CA3, were activated in association with the execution of spatially defined learned behaviors. The organization of hippocampal outputs is further suggestive of such an idea. Field CA3 projects massively to the lateral septum (Swanson and Cowan, 1977), which, in turn, densely innervates the lateral hypothalamic region (Swanson, 1977). At least some component of the latter connection is GABAergic (Stevens et al., 1987; Gritti et al., 1994), suggesting that the CA3-septalhypothalamic circuit is inhibitory in nature. The CAl region of hippocampus, in contrast, sends most of its efferents to the subiculum and retrohippocampal cortex, areas that project to ventral striatum (nucleus accumbens), anterior olfactory nucleus, neocortex (Jay and Witter, 1991), and into the Papez circuit (Witter et al., 1989; Van Groen and Wyss, 1990). The two hippocampal outputs are thus directed at very different targets that have been associated with different types of behavior (Evarts et al., 1984; Chozick, 1985; Brooks, 1988; Koob et al., 1991; Mogenson and Yang, 1991; Salamone, 1992). This could indicate that a unitary function of hippocampus involves coordinated actions on hypothalamic and striatally organized responses; an argument of this kind seems reasonable, given that the great majority of CA1 afferents arise in CA3 (Amaral and Witter, 1989) and, hence, it can be assumed that events in the two regions are tightly correlated. However, it remains possible that the several subdivisions of hippocampal formation, differentiated as they are with regard to anatomy and physiology, provide for distinctly different operations and therefore may differentially contribute to behavior across circumstances.

It would be of considerable interest with regard to the two broad hypotheses just described to test if the relative balance of aggregate neuronal activity in fields $\mathrm{CA} 3$ and $\mathrm{CA} 1$ remains constant or changes as animals are presented with different types of problems. The former result would support the idea that the hippocampus acts in a unified fashion, while the latter would suggest that its output systems can operate somewhat independently, and thereby selectively influence different categories of behavior.

The present experiments used c-fos expression to test if relative activity in CA 3 versus CA1 shifts with behavioral demands and to compare changes in patterns of activity in hippocampus with extrahippocampal structures presumed to be engaged in the learned olfactory discrimination task. Three groups of rats were compared: (1) home cage controls (i.e., no behavioral training), (2) animals trained to nose poke at several sites in an open field for a water reward, and (3) a group trained first to nose poke but then required to discriminate between two odors for reward. Successful performance for the third group thus required a switch from visually guided to odor-guided behaviors. Levels of c-fos mRNA were assessed in the hippocampal subdivisions as well as in sensory-motor structures required for performance in the behavioral paradigms, that is, superior colliculus, visual cortex, olfactory bulb, and piriform cortex.

\section{Materials and Methods}

\section{Animals}

Young male Wistar rats from Hilltop Laboratories (26-34-d-old at sacrifice) were used. They were housed in transparent Plexiglas cages (12 $\left.\times 22^{\prime \prime}\right)$ in groups of four to six on a regular $12 \mathrm{hr}$ day-night cycle. Animals were placed on a Harlan-Teklad fat sufficient test diet in order to decrease cage odor. Food was given ad libitum, but rats were water deprived and allowed to drink from a glass bowl placed in the cage for $\sim 8 \mathrm{~min} / \mathrm{d}$. Animals were handled for approximately $2 \mathrm{~min} / \mathrm{d}$ following behavioral training sessions.

\section{Training apparatus}

The olfactory discrimination training apparatus (similar to that described by Staubli et al., 1989) is an open wedge-shaped chamber (116 $\mathrm{cm}$ long, $81 \mathrm{~cm}$ wide, $39 \mathrm{~cm}$ high) with an extension at its thin end that serves as a starting compartment $(32 \times 30 \mathrm{~cm})$. Six holes $(2 \mathrm{~cm}$ diameter), spaced evenly in the horizontal plane, were placed $3.5 \mathrm{~cm}$ above the floor on the opposite wall of the wedge. Six additional holes $(1.5 \mathrm{~cm}$ diameter), placed directly underneath the first, contained protruding glass connectors and served as outlets for the odor-carrying tubes. Wall dividers ( $31 \mathrm{~cm}$ high, $25 \mathrm{~cm}$ long) were inserted between the outlets, which created six separate short "odor alleys" (entrance width of $13 \mathrm{~cm}$ ). A $1 \mathrm{ml}$ syringe was used to administer $0.025 \mathrm{ml}$ water reward through the holes for every correct response. A strobe light was mounted $8 \mathrm{~cm}$ above the test apparatus and flashed for $2 \mathrm{sec}$ following incorrect responses. Olfactory discrimination training was conducted in a dimmed room.

Odors were generated by forcing 7 liters $/ \mathrm{min}$ of air through $125 \mathrm{ml}$ flasks containing $\sim 16 \mathrm{ml}$ of either pure peppermint extract (Schilling; Hunt Valley, MD) or amyl acetate (Fisher, Tustin, CA). A 1:12 dilution of saturated odor vapor in air was used for both odors in the discrimination problem. These dilutions were chosen in an attempt to match perceived odor intensities. The outlet of each flask was connected to Tygon tubing $(0.5 \mathrm{~cm}$ inner diameter) that carried the odorized air and ejected it into the training apparatus through a given odor outlet during trials. In order to interrupt the odor release between trials, the air was diverted to an exhaust valve that was placed in the line ahead of the odor flasks.

\section{Odor training procedure}

Nose poking. Rats were traincd to poke their noses through the six large holes (above the odor ports) for water reward. Each nose poke was rewarded with $0.025 \mathrm{ml}$ water delivered from a syringe held through the hole. Following such a response, animals were picked up and placed back in the starting compartment to begin the next trial. A cardboard door separated the starting chamber from the rest of the apparatus, and was lifted at the beginning of every trial. At this stage, nose pokes were rewarded at every hole as Jong as they occurred within 1 min of the beginning of the trial. However, successive pokes at the same hole (over two consecutive trials) were not reinforced. On occasion, exception was made to this final task criterion. This was true particularly in the case of one rat that would become fearful and stop responding if consecutive nose pokes in the same location were not rewarded. This animal was, nevertheless, included in the study because its exclusion did not significantly change any of the data.

Odor discrimination. After nose-poke training, some of the animals performed on a two-odor discrimination problem. Rats learned to nose poke at the positive odor (peppermint), which was reinforced with water, and to avoid the negative odor (amyl acetate), poking at which resulted in a mildly aversive $2 \mathrm{sec}$ strobe flash. For each trial, the odors were randomly assigned to two of the six arms. The odors were turned off $2 \mathrm{sec}$ after the nose poke. Nose pokes into unassigned holes had no consequence. However, if no correct or incorrect response occurred within $1 \mathrm{~min}$, the trial was terminated, the odors turned off, and the animal returned to the start chamber.

\section{Animal treatment groups}

Home cage controls (group 1). In order to determine baseline levels of c-fos mRNA expression, five rats were killed without undergoing any type of experimental manipulation. They were taken from the home cage, anesthetized, and intracardially perfused with paraformaldehyde, as described below. Cage controls were not water deprived or handled.

Nose pokers (group 2). To determine the effects on c-fos mRNA expression of exposure to the odor-discrimination training apparatus, actively nose poking for water reward, and being handled by the experimenters, seven animals underwent the above-described nose-poke training for $30 \mathrm{~min} / \mathrm{d}$ for $4 \mathrm{~d}$. On the fifth day, they again performed the nose-poke task, but this time were kept in the training apparatus 
until they became satiated and stopped responding (57 $\pm 8 \mathrm{~min} ; 152$ \pm 33 trials). Immediately following this session, animals were injected with an overdose of sodium pentobarbital and perfused with $4 \%$ paraformaldehyde. Animals were killed over the course of several days (3$4 \mathrm{~d})$. Therefore, in order to prevent deterioration of the nose-poking response, those not being killed on a particular day performed an additional 15 min nose-poking session each day before the final test session.

Two-odor discrimination group (group 3). In order to ascertain the effect of training on a two-odor discrimination in a familiar environment, c-fos mRNA levels were examined in six animals that were taken one step further than nose pokers. Following completion of the four nose-poke sessions, these animals learned the odor-discrimination problem (see above). Rats performed on $117 \pm 36$ trials before reaching learning criteria: $80 \%$ correct choices in a block of 10 trials and active avoidance of the negative odor. The time at which criterion was reached was noted, and rats were required to maintain such a level of performance for an additional $30 \mathrm{~min}$. At the end of the $30 \mathrm{~min}$, animals were killed. This time point was chosen because c-fos mRNA levels have been shown to peak at about $30 \mathrm{~min}$ following various stimulation paradigms (Shin et al., 1990; see Morgan and Curran, 1991, for review). Overall, animals in this group completed $168 \pm 33$ trials in $112 \pm 19$ min.

\section{In situ hybridization}

Levels of c-fos mRNA were examined in tissue sections cut throughout the rat brain using in situ hybridization of a ${ }^{35} \mathrm{~S}$-labeled cRNA probe complementary to rat c-fos mRNA (i.e., to positions 583-1250 of clone pc-fos (rat)- 1 by Curran et al., 1987). The antisense cRNA was transcribed from Pst I-linearized recombinant clone $\mathrm{pBS} / \mathrm{rfos}$ with T7 RNA polymerase in the presence of uridine $5^{\prime}-\left[\alpha-\left[{ }^{35} S\right]\right.$ thio $]$ triphosphate. The sense RNA sequence was generated from the same template using T3 RNA polymerase after linearization with EcoRI.

Animals were intracardially perfused with $4 \%$ buffered paraformaldehyde, and their brains processed for in situ hybridization as described in detail elsewhere (Gall et al., 1991; Lauterborn et al., 1993). Brains were postfixed for $2 \mathrm{~d}$ and then placed in $20 \%$ sucrose in $4 \%$ paraformaldehyde for another $2 \mathrm{~d}$. Coronal $30 \mu \mathrm{m}$ thick tissue sections were cut on a freezing microtome and collected into $4 \%$ paraformaldehyde. Hybridization was conducted at $60^{\circ} \mathrm{C}$ for $38-40 \mathrm{hr}$ with a cRNA concentration of $1 \times 10^{6} \mathrm{cpm} / 100 \mu \mathrm{l}$. The distribution of hybridization was evaluated using Amersham $\beta$-max Hyperfilm and Kodak NTB2 emulsion autoradiography with exposure intervals of $1-2 \mathrm{~d}$ and $2-3$ weeks, respectively. No cellular labeling was seen in tissue hybridized to the sense probe or treated with ribonuclease A before hybridization.

\section{Autoradiographic analysis}

Densitometric analysis of film autoradiograms was carried out using the MicroComputer Imaging Device (Imaging Research, St. Catherine's, $\mathrm{ON}$, Canada). Autoradiograms were calibrated relative to ${ }^{14} \mathrm{C}$-labeled brain paste standards that allowed the conversion of optical density readings to $\mathrm{cpm} / 25 \mu \mathrm{g}$ protein (see Gall et al., 1994, for details). Each brain region was sampled in a minimum of four to five sections at different rostrocaudal levels. Multiple measures were collected to determine a mean value per section and then the mean and standard deviation of these section means was calculated. Hippocampal measure ments were made from film that had undergone a 2 d exposure, while all other regions were sampled from film exposed for $1 \mathrm{~d}$. Hybridization of the c-fos cRNA was quantified in the following brain areas: (1) intermediate levels of the main olfactory bulb, granule cell layer, and periglomerular aspects of the glomerular layer (where focal points of c-fos mRNA induction for peppermint and amyl acetate odor have been observed) (Guthrie et al., 1993, and unpublished observations); (2) medial and lateral aspects of the superficial gray layer of superior colliculus (as defined by Paxinos and Watson, 1986); (3) layer II of rostral piriform cortex (through the level of septum); (4) superficial (layers II/III) and deep (layers V/VI) rostral occipital cortex [areas $2 \mathrm{MM}, 2 \mathrm{ML}$, and $2 \mathrm{~L}$ as defined by Paxinos and Watson (1986)], which lie dorsal to the hippocampus and lateral to retrosplenial cortex; and (5) rostral hippocampus-pyramidal cell fields CAIb and CA3 and the suprapyramidal blade of stratum granulosum. Since the precise boundaries of field CA1 are difficult to distinguish in film autoradiograms, only the central portion, overlying the dorsal blade of the dentate gyrus, was analyzed. As detailed in the Results section, ratios in the labeling densities of brain regions were often calculated to identify changes in the relative balance of hybridization between areas in the same animal and to reduce interanimal variability for purpose of comparison. Two-tailed $t$ tests, analyses of variance (ANOVAs), and linear regression analyses were used for statistical comparisons. The Fisher PLSD and Sheffe $F$ test were used for post hoc comparisons. A 95\% confidence level had to be reached for differences to be considered significant $(p \leq 0.05)$.

\section{Results}

Visual system

Figure 1 illustrates the sampling areas for the superior colliculus and visual cortex and shows representative cases for each of the three groups. Expression of c-fos mRNA was very low in cage controls (group 1), highest in the animals in the nose-poke group (group 2), and intermediate in the two-odor discrimination group (group 3). Quantitative comparisons, summarized in Figure 2, show that nose-poke training increased c-fos mRNA in superior colliculus and visual cortex. The two-odor discrimination group showed the same general pattern of increased hybridization as group 2, although the relative difference between medial and lateral superior colliculus was not as great; that is, the medial to lateral ratio was $2.32 \pm 0.44$ (mean $\pm S D$ ) for group 2 and $1.76 \pm 0.24$ for group 3 ( $p<0.02$, unpaired $t$ test). Furthermore, the increased expression in the visual cortex was relatively smaller in group 3 than in group 2; that is, the ratio of cortex to tectum was $1.16 \pm 0.23$ for group 2 and $0.86 \pm 0.09$ for group 3 ( $p<0.02$, unpaired $t$ test). Thus, there were significant differences in the pattern of c-fos mRNA induction as well as absolute differences in hybridization densities produced by the two behavioral paradigms.

\section{Olfactory system}

Figure 3 illustrates the levels of c-fos cRNA hybridization in the olfactory bulbs of rats from each of the three groups. The results for the home cage group were bimodal: two rats had high levels of expression while the remaining three did not. The example presented is from the "low" expression subgroup; as shown, labeling was of comparable density in the glomerular and granule cell layers. Quantitative measures from olfactory bulb for the three groups are summarized in Figure 4. Because of the variability of the home cage group, it was not possible to determine if the two experimental paradigms significantly increased c-fos mRNA content, although the values for group 2 differed significantly from those for group 3 . Labeling at the four sites was highly correlated within each group. In Figure $4, b$ and $c$ show the ratio of labeling densities within the medial and lateral glomerular and granule cell layers and highlight the marked difference in the distribution of hybridization within olfactory bulb of olfactory discrimination as compared to cage-control and nose-poke rats. For the cage-control and nose-poke groups, labeling was slightly lower in lateral than in medial aspects of the olfactory bulb. This difference was significant for group 2 ( $p<$ 0.02 , paired $t$ test), and this was more pronounced for the glomerular (Fig. $4 b$ ) than the granule (Fig. $4 c$ ) cell layer. The pattern was reversed for rats trained on the two-odor discrimination; that is, the combined lateral sites had $24 \pm 12 \%$ more labeling than the combined medial sites ( $p<0.002$, paired $t$ test). The differences in ratios between rats trained on the odor discrimination versus those in the other two groups was also highly significant $(p<0.002$, unpaired $t$ test). Finally, the increase in $c$-fos mRNA expression in the lateral zone of the bulb in the odor-trained rats was greater for the granule cell layer than for 

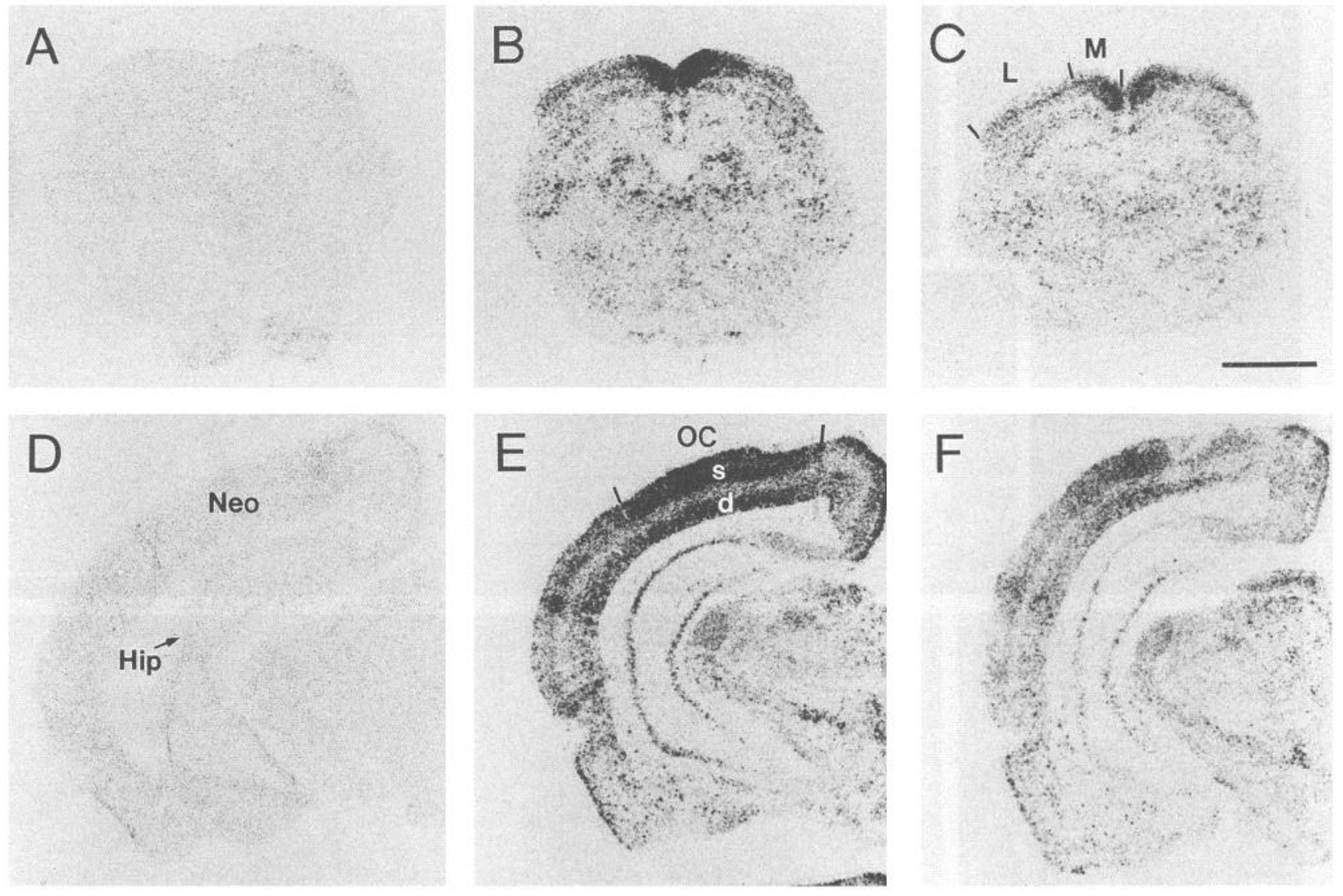

Figure 1. c-fos mRNA expression in the visual system. Bright-field photomicrographs of film autoradiograms showing levels of c-fos cRNA hybridization in sections through the superior colliculus $(A-C)(M$, medial; $L$, lateral, sectors bracketed) and the occipital cortex $(O C)(D-F)$ for the three animal treatment groups. Basal levels of c-fos mRNA expression were uniformly low in cage controls $(A$ and $D)$. Labeling was dramatically increased above these control levels in the nose-poke group $(B$ and $E)$ in most regions, but particularly in the medial superior colliculus $(M)$ and superficial $(s)$ and deep $(d)$ layers of occipital cortex. Animals trained on the two odor discrimination $(C$ and $F)$ showed intermediate levels of hybridization in these regions. Note that the relative difference in labeling between the medial and lateral superior colliculus was not as great in rats trained on the discrimination $(C)$ as in the nose-poke group $(B)$. Neo, neocortex; Hip, hippocampus. Scale bar, $2 \mathrm{~mm}$.

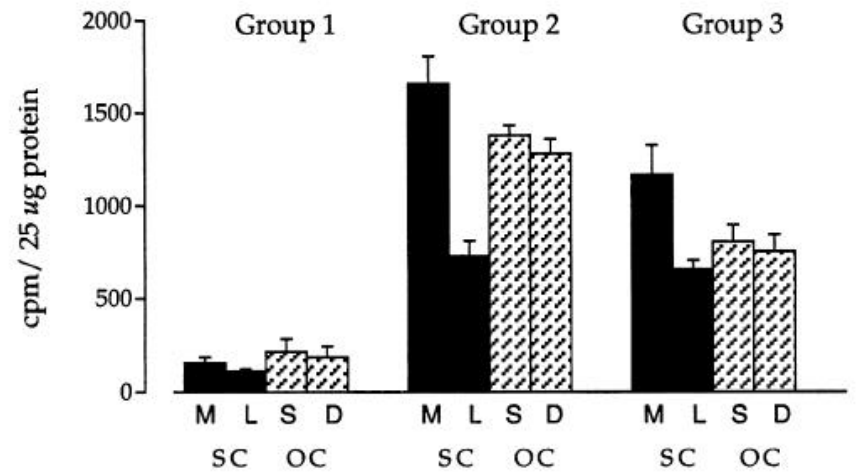

Figure 2. Bar graph showing densities of hybridization to c-fos mRNA in superior colliculus and visual cortex in the three animal treatment groups. Regions measured include medial $(M)$ and lateral $(L)$ aspects of superficial superior colliculus $(S C)$, and superficial $(S)$ and deep $(D)$ layers of occipital cortex $(O C)$ (see Fig. 1 for fields measured). Bars indicate group mean values ( \pm standard error). Expression of c-fos mRNA was very low in home cage controls (group 1), highest in the nose-poke group (group 2), and intermediate in the odor-discrimination group (group 3). Groups 2 and 3 showed the same general pattern of increases in c-fos mRNA (relative to cage-controls), although the relative difference between medial and lateral superior colliculus was smaller in group $3(p<0.02$, unpaired $t$ test) and labeling of visual cortex was relatively smaller in group 3 than in group $2(p<0.02$, unpaired $t$ test). the glomerular layer $(13 \pm 19 \%, p<0.05$, paired $t$ test, see Fig. $4 b, c)$.

Representative cases of labeling in the piriform cortex are shown in Figure 3, and quantitative comparisons are summarized in Figure 5. The pattern was similar to that obtained in visual cortex: c-fos cRNA hybridization was greatest in nose-poke animals (group 2), least in the home cage controls, and intermediate in the rats trained on a two-odor discrimination. The two experimental groups were not significantly different, but both were significantly different from group 1 controls $(p<0.02$, unpaired $t$ test).

It should be noted that levels of c-fos mRNA expression in control brains were higher in piriform cortex than in any other region sampled other than olfactory bulb. Accordingly, increases found in the two experimental groups, while large, were not proportionately as great as those recorded in the visual system. Comparing Figure 2 with Figure 5, it also appears that the expression in piriform cortex was about the same as that for visual cortex in the nose-poke group but somewhat greater in the odordiscrimination group. Expression in piriform versus visual cortex was greater in the rats trained on odor cues $(34 \pm 31 \%, p<$ 0.05 , paired $t$ test), but was not detectably different in the nosepoke group $(1 \pm 24 \%)$; the difference in relative expression between these two groups was marginally significant $(p<0.07$, 

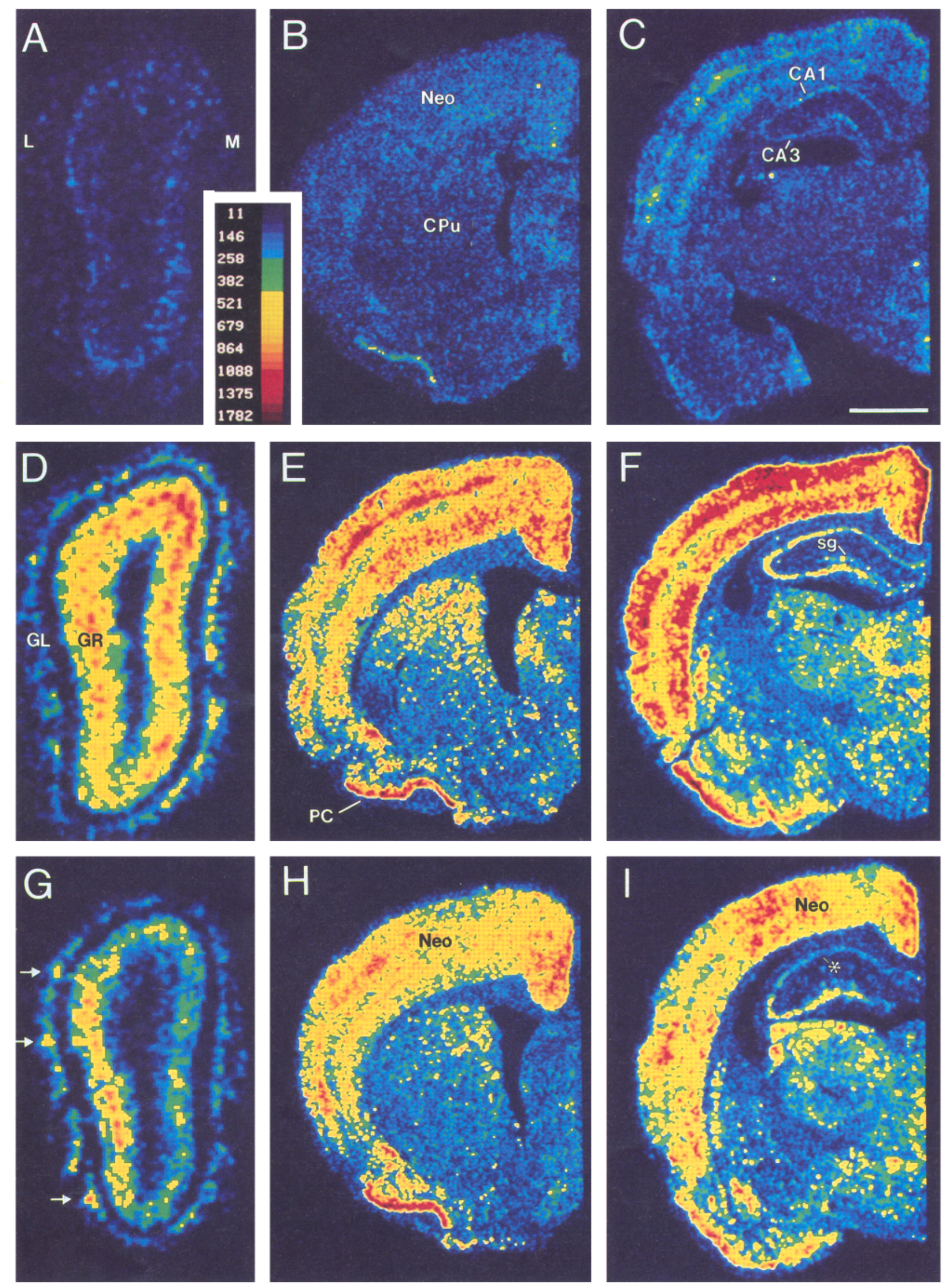

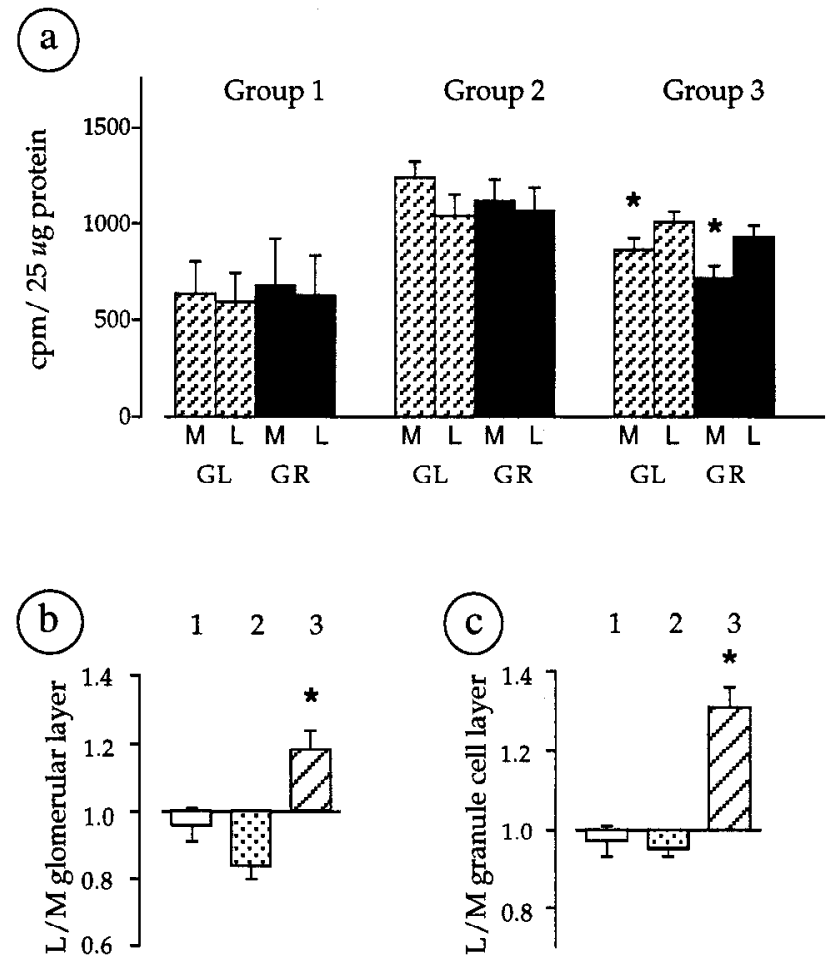

Figure 4. Bar graphs illustrating (a) mean levels of c-fos cRNA hybridization in the main olfactory bulbs for each of the three treatment groups, and $(b$ and $c$ ) medial-lateral comparisons for the granule and glomerular neurons. Regions measured include the medial $(M)$ and lateral $(L)$ glomerular layer $(G L)$ and the medial and lateral granule cell layer $(G R)$. Values for the nose-poke group (group 2) differed significantly from those of rats trained on the two-odor discrimination (group 3) (ANOVA). Group 3 had significantly lower levels of c-fos expression than group 2 in the medial glomerular $(* p \leq 0.01)$ and medial granule cell layers $\left({ }^{*} p \leq 0.02\right)$ (Fisher PLSD and Sheffe $F$ tests). Labeling at the four sites was highly correlated within each group. Differences in ratios between odor-discrimination rats versus nose-pokers and cagecontrols (group $I$ ) was also highly significant (unpaired $t$ test, ${ }^{*} p<$ 0.0005 for granule cells, ${ }^{*} p<0.03$ for glomerular cells).

unpaired $t$ test). Comparison of animals within each group revealed that the values for the two cortical regions were modestly correlated ( $r=0.70$ for group 2 and $r=0.85$ for group 3).

\section{Hippocampus}

Representative sections through rostral hippocampus are shown in Figure 3. In home cage-control rats, expression was uniformly low, and there were no evident differences between the dentate gyrus and the two pyramidal cell fields. Densitometric results

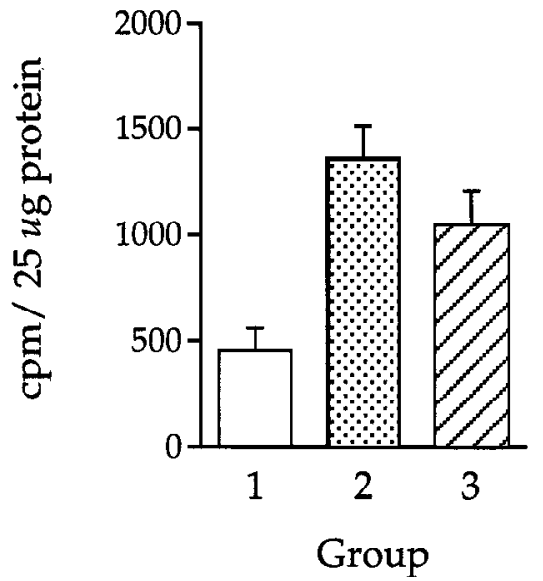

Figure 5. Bar graph showing levels of c-fos cRNA hybridization in piriform cortex for the three animal treatment groups: (1) cage controls, (2) nose pokers, and (3) animals trained on the two-odor discrimination. Bars indicate group mean values ( \pm standard error). Groups 2 and 3 were significantly different from the controls ( $p<0.02$, unpaired $t$ test), but the differences between them were not statistically significant.

for the control, nose-poke, and odor-discrimination groups are summarized in Figure 6. Expression was substantially greater than control values in fields CA 3 and CA1 but not in the dentate gyrus granule cell layer of the nose-poke group. The dentate gyrus thus constitutes the only brain region examined in which c-fos mRNA was not increased in group 2 animals. Enhanced expression appeared to occur to about the same degree in fields $\mathrm{CA} 3$ and $\mathrm{CA} 1$ in the nose-poke group. Within-animal comparisons were made to examine this point more closely. Labeling values for the two subfields were correlated $(r=0.84)$, and when expressed as ratios confirmed that there were no appreciable differences between $\mathrm{CA} 3$ and $\mathrm{CA} 1$ in the nose-poke group (i.e., $\mathrm{CA} 3$ was $8 \pm 24 \%$ greater than CA1; see Fig. 6 , right). It was noted that levels of $\mathrm{c}$-fos expression were often not uniform throughout field CA1 of nose-poke animals. There was a visible trend for less labeling in the portion of CA1 closest to the subiculum (i.e., CA1a; see Fig. $3 F$ ), although this span of CAl was not measured. The odor-discrimination rats also gave no evidence of c-fos mRNA induction in the dentate gyrus. Expression was elevated in field CA3 and to a level slightly greater than that observed for the nose-poke animals. Field CAl also had c-fos mRNA levels that were elevated above control values, but the magnitude of this effect was much smaller than that obtained for field CA3 $(p<0.005$, unpaired $t$ test) or field CA1 of the nose-poke group ( $p<0.004$, unpaired $t$ test). Interestingly

$\leftarrow$

Figure 3. c-fos mRNA expression in the olfactory system and hippocampus. Calibrated pseudocolor images of film autoradiograms showing densities of hybridization to c-fos mRNA at the level of the main olfactory bulb $(A, D$, and $G)$, rostral piriform cortex $(B, E$, and $H)$, and rostral hippocampus $(C, F$, and $I)$ for individual rats from each of the three treatment groups. In cage-control rats $(A-C)$, c-fos mRNA levels were very low. In the nose-poke group $(D-F)$, hybridization densities were dramatically increased above control levels. Particularly dense labeling was observed in piriform cortex $(P C)$ and neocortex (Neo). Note that c-fos expression is comparable in medial $(M)$ versus lateral $(L)$ regions of the granule $(G R)$ and glomerular layers $(G L)$ of olfactory bulb $(D)$ and approximately equivalent in pyramidal cells of subfields CA3 versus CA1 in the hippocampus $(F)$ of this group. Animals trained on the two odor discrimination $(G-I)$ can be seen to exhibit intermediate levels of c-fos mRNA expression. Neocortical regions, dorsolateral caudate-putamen $(\mathrm{CPu})$, medial olfactory bulb, and region CA1 pyramidal cells (asterisk) appear less densely labeled in this group as compared to the nose-poke group $(D-F)$, although the piriform cortex, lateral olfactory bulb, and region CA3 pyramidal cells show approximately equal labeling. These differences in labeling result in distinct patterns of hybridization for olfactory bulb and hippocampus of odor-discrimination rats. In the bulb, three lateral foci of activation are apparent in the glomerular layer (arrows) and in underlying granule cell fields. This pattern of activation corresponds to that observed for peppermint odor, the positive, most frequently sampled odor in the paradigm. The values on the color calibration bar are in $\mathrm{cpm} / 25 \mu \mathrm{g}$ protein. Scale bar: $661 \mu \mathrm{m}$ for $A, D$, and $G ; 1613 \mu \mathrm{m}$ for $B, C, E, F, I I$, and $I . s g$, stratum granulosum. 


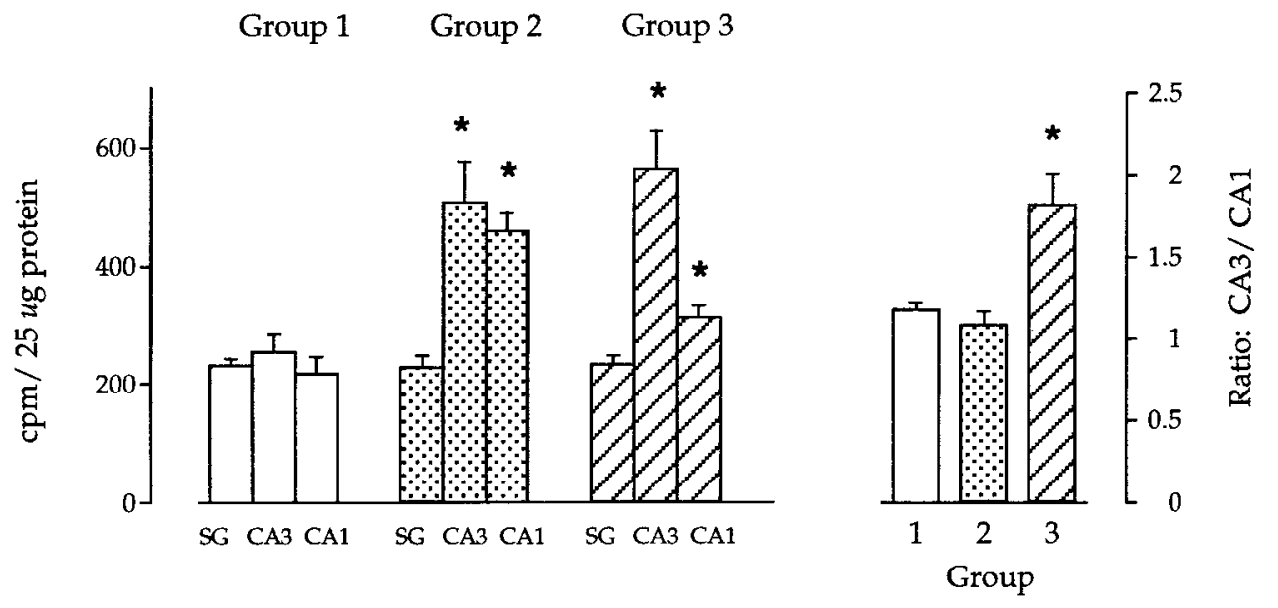

Figure 6. Bar graphs showing densities of hybridization to c-fos mRNA in rostral hippocampus [i.e., stratum pyramidale fields CA1 and CA3 and suprapyramidal stratum granulosum $(S G)$ ] for the three treatment groups, and ratios of c-fos cRNA hybridization in CA3/CA1. Expression was uniformly low, and there were no evident differences between the two pyramidal cell fields and the granule cells in control rats ( $g$ roup 1 ). Expression was significantly increased above control values in fields CA1 and CA3, but not in the granule cells of the nose-poke group (group 2). There were no appreciable differences between $\mathrm{CA} 3$ and $\mathrm{CA} 1$ in the nose-poke group, as confirmed when expressed as ratios. In odor-discrimination rats (group 3 ), hybridization was low in stratum granulosum but markedly elevated in field CA3; hybridization in CA1 was greater than control values, but this difference was much smaller than that obtained for field CA3 $\left({ }^{*} p<0.005\right.$, unpaired $t$ test) or for field CA1 of the nose-poke group (* $p<$ 0.004 , unpaired $t$ test). The CA3 to CA 1 ratios were much greater for group 3 than for the other two groups ( ${ }^{*} p<0.02$, unpaired $t$ test).

enough, the correlation in c-fos values obtained for the control and nose-poke groups was substantially reduced in odor-discrimination rats $(r=0.40)$, indicating that some factor acting differentially on one of the subdivisions was weak or absent with regard to the other.

As expected from the group means, within-animal comparison ratios of $\mathrm{CA} 3$ to $\mathrm{CA} 1$ values were much greater for group 3 than for the other two groups (Fig. 6, right). The magnitude of the difference was the largest of any of the within-animal comparisons made in this study; that is, the odor discrimination paradigm produced at least as great a differentiation of hippocampal labeling relative to controls as it did for the olfactory bulb.

\section{Discussion}

The above results indicate that the subdivisions of hippocampus respond differentially across behaviors. Levels of c-fos mRNA in dentate gyrus, CA3, and CA1 were highly correlated with those in other brain regions (e.g., visual cortex, $r>0.95$ ) in home cage controls. This suggests that expression throughout the brain, including hippocampus, was strongly influenced by some generalized factor, although not in a quantitatively uniform fashion (i.e., the slopes of the relationships varied considerably, depending upon the regions being compared). Performance of a well-learned nose-poke paradigm disrupted the relationship between expression in hippocampus and other regions (e.g., stratum granulosum vs visual cortex, $r=0.32$; CA3 vs visual cortex, $r=0.13$ ) and strongly affected the pattern of expression within the hippocampus. The dentate gyrus, alone of all brain regions sampled, exhibited no evidence for increased c-fos mRNA content in the nose-poke animals, a result that was somewhat surprising given that $\mathrm{c}$-fos expression in the granule cells is known to be responsive to a wide variety of manipulations. Following generalized seizure activity or kindling stimulation, the most dramatic and rapid $\mathrm{c}$-fos induction occurs in neurons of the dentate gyrus (Dragunow and Robertson, 1987; Morgan et al., 1987). In contrast, c-fos mRNA concentrations were doubled in field CA3 of group 2 rats compared to levels in home cage controls. Despite the differential response of dentate gyrus and CA3 in the nose-poke paradigm, mRNA levels in the two regions remained correlated $(r=0.86)$, suggesting that variations in granule cell activity were reflected and amplified in field CA3 of animals performing the learned behavior. The CA1 region also had levels of c-fos message that were substantially greater in nose-poke than control rats with the percentage increase being about the same as that for field CA3. Within-rat comparisons indicated that expression of the proto-oncogene was correlated between CA3 and CA1 $(r=0.84)$ as expected, given the dense Schaffer-commissural projection between the two pyramidal cell regions (see Amaral and Witter, 1989, for review).

There was no evidence of increased c-fos expression in the dentate gyrus of rats trained on olfactory discrimination, although an increase in message was evident in the CA3 pyramidal neurons. Despite this differentiated induction, e-fos mRNA expression in the two subfields was highly correlated $(r$ $=0.92$ ). Thus, the first two stages of hippocampal circuitry appeared to behave in the same manner in the nose-poke and odordiscrimination paradigms. Aggregate activity in field CA1, however, was quite different in the two conditions. Induction of c-fos mRNA was much less pronounced than that found in CA3 of the odor-discrimination rats or in CA1 of the nose-poke animals. Moreover, the correlation between CA3 and CA1 obtained in the cage-control and nose-poke groups was absent $(r=0.40)$ in the animals trained on odors. Thus, a condition of "CA3 dominance" was apparent in group 3 (i.e., CA3 expression was $82 \%$ greater than CA1 expression) but not in the other two groups; this was the largest relative effect of behavior recorded in the study.

In all, hippocampal c-fos mRNA expression in cage-control rats appeared to be regulated by variables acting throughout much of the brain; these influences were superseded in both groups of trained animals by some factor(s) that enhanced expression in CA3 over that occurring in the dentate gyrus. The septohippocampal projections provide a logical candidate for this factor. These afferents could produce variable levels of ac- 
tivity in the dentate gyrus leading to changes in mossy fiber input to field CA3; this, combined with a direct action of the septal projections on CA3, could result in the observed amplification effect (see Swanson, 1977; Lynch et al., 1978 for a description of septohippocampal projections). The breakdown of the correspondence in expression between $\mathrm{CA} 3$ and $\mathrm{CA} I$ that occurred with odor training has to be viewed as surprising, because the latter region receives a very large percentage of its excitatory input from the former (Amaral and Witter, 1989); that is, it would be assumed that any changes in the aggregate activity of the CA3 pyramidal cells would be reliably reflected in the aggregate activity of their CA1 target cells. The possibility exists that the diffuse, ascending projections ( $\mathrm{ACh}, \mathrm{NE}, 5-\mathrm{HT}$ ) to the two subfields are anatomically differentiated to a degree that is sufficient to allow for differential effects on their interneuron populations (Miettinen and Freund, 1992), and it would be of interest in this regard to test if antagonists of cholinergic or serotonergic receptors eliminate the disparity in c-fos mRNA expression between CA 3 and CA1. Indeed, there is evidence for distinct sources of cholinergic (Lynch et al., 1978; Nyakas et al., 1987) and entorhinal (Steward, 1976) innervation of the two hippocampal subfields. Moreover, modeling studies have raised the possibility that LTP-like strengthening of synapses can lead to a paradoxical decrease in overall network activity by producing rapid and synchronous activation of a small set of target neurons that then, via recurrent inhibition, suppress firing by their neighbors (Coultrip et al., 1992).

Whatever its origin, the marked change in the relative balance of activities in CA3 versus CA1 that occurred with the shift between the two behavioral paradigms supports the idea that the hippocampus has more than one mode of operation. Equivalent levels of activity in the two output systems of hippocampus during the nose-poke task would be expected to favor a balance in the behaviors organized by the septohypothalamic versus striatocortical systems. The hippocampus has long been implicated in the inhibition of prepotent responses (Douglas, 1967; Kimble, 1968; Gray, 1982) and the CA3-lateral septal-lateral hypothalamic circuit seems well suited for such a function, that is, excitation (CA3 to septum) of a GABAergic (septum-hypothalamus) connection (Swanson and Cowan, 1977; Stevens and Cotman, 1986; Stevens et al., 1987; Gritti et al., 1994). Recent studies suggest that subicular projections to ventral striatum are targeted for GABAergic interneurons (Pickel et al., 1988; Meredith et al., 1990; Sesack and Pickel, 1990); from this, it would be expected that increased activity in CA1 would lead to greater inhibition of ventral striatum. Taken together, these observations suggest that the hippocampus exerts an equivalent suppression of hypothalamic and striatal components of behavior during the nose-poke task. The same line of reasoning suggests that the pronounced disparity between CA3 versus CA1 would lead to a selective enhancement of the striatal contributions to behavior vis à vis those of the lateral hypothalamus in the odor-discrimination paradigm. Interesting, with regard to this hypothesis, is that the hippocampal-ventral striatal axis is thought to act as an "attentional gate" (Margulies, 1985). Specifically, connections from CA1 through subiculum to nucleus accumbens have been proposed to be involved in integrating new noteworthy events into ongoing thought or behavior (Margulies, 1985). Therefore, the distinct pattern of neuronal activation observed in the hippocampus during odor discrimination may reflect a "selective attention" function.

Another possibility is that the unusually dense commissural- associational systems that dominate the input to region CA3 (Swanson et al., 1978; Amaral and Witter, 1989) sustain regenerative patterns of activity during odor discrimination that are reflected in increased c-fos mRNA expression. Network models by Traub et al. (1989) suggest that self-sustained, recurrent activity patterns can propagate throughout the interconnected neurons of subfield CA3. Sustained activation of these neurons could provide for the association between cues separated in space and time (i.e., odor cues with water or strobe) (Lynch et al., 1991).

\section{c-fos expression in sensory areas}

As discussed, levels of c-fos expression were assessed in olfactory and visual regions as measures of the selectivity of any changes occurring in hippocampus. These analyses demonstrated a generalized influence of activity and/or arousal acting across brain areas in the performance of the nose-poke task and, by comparison with hippocampal measures, demonstrated the specialized involvement of hippocampal subfields in odor discrimination. Moreover, analysis of olfactory bulb indicated differential activation in this region with odor-discrimination training that may be involved in task acquisition.

It is important to note that by design the nose-poke and odordiscrimination paradigms were similar in many regards. Both involved serial trials and the same locomotor responses (nose pokes) for the same reward (water). Animals in each group received extensive familiarization and training prior to the last day of the experiment and on that day obtained a large number of rewards. Surprisingly, the rats presented with new contingencies and novel odor cues (group 3) had lower levels of c-fos mRNA expression in sensory pathways than those continued on the nose-poke paradigm (group 2). This suggests that the introduction of more stringent requirements for reward resulted in more specific or differentiated patterns of brain activity. Thus, in visual cortex, mRNA levels were about $70 \%$ greater in nose-poke versus odor-discrimination rats. In the olfactory bulb, nose-poke animals had greatly elevated levels of expression in both medial and lateral sectors, whereas animals trained on the odor discrimination had substantially lower levels of labeling in the medial bulb. Previous work from this laboratory has demonstrated that continuous ( $5 \mathrm{~min}$ ) exposure to odor in a controlled environment activates c-fos expression by olfactory bulb neurons with the topography of activation being odor specific (Guthrie et al., 1993). Peppermint was the predominant odor sampled in group 3 rats, and this odor is known to be represented in the lateral bulb (Coopersmith and Leon, 1984; Guthrie et al., 1993). The present findings provide the first demonstration that regionally differentiated changes in c-fos expression can be elicited with briefer odor exposures in an open field.

Two types of hypotheses could account for the pattern of results observed: (1) introduction of olfactory cues leads to the reduction of a generalized influence (e.g., arousal) that allows a differentiated response by olfactory regions of brain to emerge or (2) odor discrimination is associated with an elimination of many behaviors occurring in the nose-poke paradigm and this is reflected in the activity patterns in the brain. It is also possible that both ideas are correct; that is, identification of a single salient cue results in a reduction in diffuse systems as well as a stereotyping of behavior.

\section{References}

Amaral DG, Witter MP (1989) The three-dimensional organization of the hippocampal formation: a review of anatomical data. Neuroscience 31:571-591. 
Brennan PA, IIancock D, Keverne ED (1992) The expression of the immediate-early genes c-fos, egr-l and c-jun in the accessory olfactory bulb during the formation of an olfactory memory in mice. Neuroscience $49: 277-284$

Brooks CMC (1988) The history of thought concerning the hypothalamus and its functions. Brain Res Bull 20:657-667.

Buzsaki G (1989) Two-stage model of memory trace formation: a role for "noisy" brain states. Neuroscience 31:551-570.

Chozick BS (1985) The behavioral effects of lesions of the septum: a review. Int J Neurosci 26:197-217.

Coopersmith R, Leon M (1984) Enhanced neural response to familiar olfactory cues. Science 225:849-51.

Coultrip R, Granger R, Lynch G (1992) A cortical model of winner take all competition via lateral inhibition. Neural Networks 5:47-54.

Curran T, Gordon MB, Rubino KL, Sambucetti LC (1987) Isolation and characterization of the c-fos (rat) cDNA and analysis of posttranslational modification in vitro. Oncogene 2:79-84.

Douglas RJ (1967) The hippocampus and behavior. Psychol Bull 67: 416-442.

Dragunow M, Robertson HA (1987) Kindling stimulation induces c-fos protein(s) in granule cells of the rat dentate gyrus. Nature 329:441442 .

Ehret G, Fischer R (1991) Neuronal activity and tonotopy in the auditory system visualized by c-fos gene expression. Brain Res 567 : 350-354.

Eichenbaum H, Otto T, Cohen NJ (1992) The hippocampus-what does it do? Behav Neural Biol 57:2-36.

Evarts EV, Kimura M, Wurtz RH, Hikosaka O (1984) Behavioral correlates of activity in basal ganglia neurons. Trends Neurosci 7:447453.

Gall C, Murray K, Isackson PJ (1991) Kainic acid-induced seizures stimulate increased expression of nerve growth factor mRNA in rat hippocampus. Mol Brain Res 9:113-123.

Gall CM, Berschauer R, Isackson PJ (1994) Seizures increase basic fibroblast growth factor mRNA in adult rat forebrain neurons and glia. Mol Brain Res 21:190-205.

Gray JA (1982) The neuropsychology of anxiety: an enquiry in the functions of the septo-hippocampal system. London: Oxford UP.

Greenberg ME, Ziff EB, Greene LA (1986) Stimulation of neuronal acetylcholine receptors induces rapid gene transcription. Science 234 : 80-83.

Gritti I, Mainville L, Jones BE (1994) Projections of GABAergic and cholinergic basal forebrain and GABAergic preoptic-anterior hypothalamic neurons to the posterior lateral hypothalamus of the rat. $J$ Comp Neurol 339:251-268.

Guthrie KM, Anderson AJ, Leon M, Gall C (1993) Odor-induced increases in c-fos mRNA expression reveal an anatomical "unit" for odor processing in olfactory bulb. Proc Natl Acad Sci USA 90:33293333 .

Halgren E (1984) Human hippocampal and amygdala recording and stimulation: evidence for a neural model of recent memory. In: The neuropsychology of memory (Squire LR, Butters N, eds), pp 165182. New York: Guilford.

Hunt SP, Pini A, Evan G (1987) Induction of c-fos-like protein in spinal cord neurons following sensory stimulation. Nature 328:632634.

Irwin KB, Craig AD, Bracha V, Bloedel JR (1992) Distribution of c-fos expression in brainstem neurons associated with conditioning and pseudo-conditioning of the rabbit nictitating membrane reflex. Neurosci Lett 148:71-75.

Jay TM, Witter MP (1991) Distribution of hippocampal CA1 and subicular efferents in the prefrontal cortex of the rat studied by means of anterograde transport of Phaseolus vulgaris-leucoagglutinin. J Comp Neurol 313:574-586.

Kimble DP (1968) Hippocampus and internal inhibition. Psychol Bull 70:285-295.

Koob GF, Swerdlow NR, Vaccarino F, Hubner C, Pulvirenti L, Weiss F (1991) Functional output of the basal forebrain. Adv Exp Med Biol 295:291-305.

Lauterborn JC, Isackson PJ, Montalvo R, Gall CM (1993) In situ hybridization localization of choline acetyltransferase mRNA in adult rat brain and spinal cord. Mol Brain Res 17:59-69.

Lynch $G$ (1986) Synapses, circuits and the beginnings of memory. Cambridge, MA: MIT Press.
Lynch G, Rose G, Gall C (1977) Anatomical and functional aspects of the septo-hippocampal projections. CIBA Found Symp 58:5-24.

Lynch G, Larson J, Staubli U, Granger R (1991) Variants of synaptic potentiation and different types of memory operations in hippocampus and related structures. In: Memory: organization and locus of change (Squire LR, Weinberger NM, Lynch G, McGaugh JL, eds), pp 339-363. New York: Oxford UP.

Margulies DM (1985) Selective attention and the brain: a hypothesis concerning the hippocampal-ventral striatal axis, the mediation of selective attention, and the pathogenesis of attentional disorders. Med Hypotheses 18:221-264.

Meredith GE, Wouterlood FG, Pattiselanno A (1990) Ilippocampal fibers make synaptic contacts with glutamate decarboxylase-immunoreactive neurons in the rat nucleus accumbens. Brain Res 513:329334.

Miettinen R, Freund TF (1992) Convergence and segregation of septal and median raphe inputs onto different subsets of hippocampal inhibitory interneurons. Brain Res 594:263-272.

Mogenson GJ, Yang CR (1991) The contribution of basal forebrain to limbic-motor integration and the mediation of motivation to action. Adv Exp Med Biol 295:267-290.

Morgan JI, Curran T (1986) Role of ion flux in the control of c-fos expression. Nature 322:552-555.

Morgan JI, Curran T (1991) Stimulus-transcription coupling in the nervous system: involvement of the inducible proto-oncogenes fos and jun. Annu Rev Neurosci 14:421-51.

Morgan JI, Cohen DR, Hempstead JL, Curran T (1987) Mapping patterns of c-fos expression in the central nervous system after seizure. Science 237:192-197.

Nikolaev E, Kaminska B, Tischmeyer W, Matthies H, Kaczmarek L (1992) Induction of expression of genes encoding transcription factors in the rat brain elicited by behavioral training. Brain Res Bull 28:479-484

Nyakas C, Luiten PGM, Spencer DG, Traber J (1987) Detailed projection patterns of septal and diagonal band efferents to the hippocampus in the rat with emphasis on innervation of $\mathrm{CA} 1$ and dentate gyrus. Brain Res Bull 18:533-545.

O'Keefe J, Nadel L (1978) The hippocampus as a cognitive map. London: Oxford UP.

Olton DS, Becker JT, Handelmann GE (1979) Hippocampus, space, and memory. Behav Brain Sci 2:313-365.

Olton DS, Becker JT, Handelmann GE (1980) Hippocampal function: working memory or cognitive mapping? Physiol Psychol 8:239-246.

Paxinos G, Watson C (1986) The rat brain in stereotaxic coordinates San Diego: Academic.

Pickel VM, Towle AC, Joh TH, Chan J (1988) Gamma-aminobutyric acid in the medial rat nucleus accumbens: ultrastructural localization in neurons receiving monosynaptic input from catecholaminergic afferents. J Comp Neurol 272:1-14.

Sagar SM, Sharp FR, Curran T (1988) Expression of c-fos protein in brain: metabolic mapping at the cellular level. Science 240:13281331.

Salamone JD (1992) Complex motor and sensorimotor functions of striatal and accumbens dopamine: involvement in instrumental behavior processes. Psychopharmacology (Berl) 107:160-174.

Sesack SR, Pickel VM (1990) In the rat medial nucleus accumbens, hippocampal and catecholaminergic terminals converge on spiny neurons and are in apposition to each other. Brain Res 527:266-279.

Sharp FR, Gonzalez MF, Sharp JW, Sagar SM (1989) c-fos expression and $\left({ }^{14} \mathrm{C}\right) 2$-deoxyglucose uptake in the caudal cerebellum of the rat during motor/sensory cortex stimulation. J Comp Neurol 284:621636.

Shin C, McNamara JO, Morgan JI, Curran T, Cohen DR (1990) Induction of c-fos mRNA expression by afterdischarge in the hippocampus of naive and kindled rats. J Neurochem 55:1050-1055.

Squire LR (1986) Mechanisms of memory. Science 232:1612-1619.

Squire LR, Cohen NJ, Nadel L (1984) The medial temporal region and memory consolidation: a new hypothesis. In: Memory consolidation: psychobiology of cognition (Weingartner H, Parker E, eds), pp 185210. Hillsdale, NJ: Erlbaum.

Staubli U, Thibault O, DiLorenzo M, Lynch G (1989) Antagonism of NMDA receptors impairs acquisition but not retention of olfactory memory. Behav Neurosci 103:54-60.

Stevens DR, Cotman CW (1986) Excitatory amino acid antagonists 
depress transmission in hippocampal projections to the lateral septum. Brain Res 382:437-440.

Stevens DR, Gallagher JP, Shinnick-Gallagher P (1987) In vitro studies of the role of gamma-aminobutyric acid in inhibition in the lateral septum of the rat. Synapse 1:184-190.

Steward $O$ (1976) Topographic organization of the projections from the entorhinal area to the hippocampal formation of the rat. J Comp Neurol 167:285-314.

Swanson LW (1977) The anatomical organization of septo-hippocampal projections. CIBA Found Symp 58:25-48.

Swanson LW, Cowan WM (1977) An autoradiographic study of the organization of the efferent connections of the hippocampal formation in the rat. J Comp Neurol 172:49-84.

Swanson LW, Wyss JM, Cowan WM (1978) An autoradiographic study of the organization of intrahippocampal association pathways in the rat. J Comp Neurol 181:681-716.

Sybirska E, Friedman HR, Goldman-Rakic PS (1994) Double label
2-DG reveals activation of hippocampal subfields in monkey related to response direction. Soc Neurosci Abstr 20:356.

Traub RD, Miles R, Wong RKS (1989) Model of the origin of rhythmic population oscillations in the hippocampal slice. Science 243:13191325

Van Groen T, Wyss JM (1990) Extrinsic projections from area CAl of the rat hippocampus: olfactory, cortical, subcortical, and bilateral hippocampal formation projections. J Comp Neurol 302:515-528.

Wicklcgren WA (1979) Chunking consolidation: a theoretical synthesis of semantic networks, configuring in conditioning, S-R v. cognitive learning, normal forgetting, the amnesic syndrome, and the hippocampal arousal system. Psychol Rev 86:44-60.

Winson J (1984) Neuronal transmission through the hippocampus: dependence on behavioral state. In: Cortical integration (Reinoso-Suarez F, Ajmone-Marsan C, eds), pp 131-146. New York: Raven.

Witter MP, Groenewegen HJ, Lopes Da Silva FH, Lohman AHM (1989) Functional organization of the extrinsic and intrinsic circuitry of the parahippocampal region. Prog Neurobiol 33:161-253. 